\title{
THE INFLUENCE OF BOXING EXERCISES ON THE COGNITIVE PROCESSES AND SPEED OF SENSORIMOTOR REACTIONS OF 15-17 YEARS OLD BOYS
}

\author{
Alla Solovey \\ Lviv State University of Physical Culture named after Ivan Bobersky, Ukraine \\ Lyubomyr Vovkanych \\ Lviv State University of Physical Culture named after Ivan Bobersky, Ukraine \\ Nataliya Sorokolit \\ Lviv State University of Physical Culture named after Ivan Bobersky, Ukraine \\ Olga Rymar \\ Lviv State University of Physical Culture named after Ivan Bobersky, Ukraine

\section{Marta Yaroshyk} \\ Lviv State University of Physical Culture named after Ivan Bobersky, Ukraine

\section{Ivan Novokshonov} \\ Lviv State University of Physical Culture named after Ivan Bobersky, Ukraine
}

\begin{abstract}
The article is dedicated to studying of the influence of boxing trainings on thinking processes of the process of physical education and speed of sensorimotor of 15-17 years old boys. The goal of the research is optimization process of the physical education and improvement of the cognitive processes of 15-17 years old boys. The methods of the research are methodological literature analysis, psychophysiological reaction testing, applying computer complex, pedagogical experiment and mathematical statistics methods. It was proved that boxers have better ability to fast reacting ( $t=2.513$ with $p<0.05)$, higher indicators of functional level of central nervous system $(t=3.165$ with $p<0.05)$, stability of reaction ( $t=2.248$ with $p<0.05)$, better indicators of average reaction time with sound and visual interferences ( $t=3.104$ with $p<0.05)$, better indicators of attention capacity $(t=2.317)$ with $p<0.05)$. Attention diversification $(t=2.793$ with $p<0.05)$, that prove positive impact of boxing exercises on the thinking processes. There was implemented author program, applying no-contact special boxing exercises. There were 30 students, 15-17 years old, in the experiment. The indicators of the average time of the reaction (Wilcoxon criteria T.emp. $=144$ with $p<0.05$ ) and stability of reaction (Wilcoxon criteria T.emp. $=133$ with $p<0.05$ ) become better after the experiment. Other indicators like indicators of average reaction time with sound and visual interferences (Wilcoxon criteriaT.emp. $=112$ with $p<0.05$ ), indicators of attention capacity (Wilcoxon criteriaT.emp. $=61.5$ with $p<0.05$ ) and indicators of attention diversification (Wilcoxon criteriaT.emp. $=7$ with $p<0.05$ ) become better as well. The
\end{abstract}


conclusions are: the results of the research prove the effectiveness of the experimental program.

Keywords: boys, boxing, physical education, thought processes.

\section{Introduction}

In the settings of global changes in the present, successful academic and professional life strongly depend on development of memory, reaction, ability to quickly make judgments and take decisive actions, intellectual capacities, as well as toughness and durability of the central neural system. Resting on the fact of somatic and psychological health state worsening of the nowadays youth, it is extremely important to improve personal psycho-physiological functions and the overall optimal intellectual capacities. Considering that, one of the key improvement direction of the physical education at the primary, secondary, and high schools is to explore the most efficient approaches and methods to optimize the central nervous system workability taking into account the interests and favours of youth. Team sports and individual sports are among the most popular ones, especially boxing. Boxing is overwhelmingly well liked in Ukraine due to successes of Ukrainian boxers at the world stage and being ranked among top athletes in the field. Boxing athlete preparation systems incorporate cognitive capacity and sensorimotor reaction development. Both unifications and modifications of such approaches of specific sports type enable us to utilize them in the processes of youth and adolescence physical education. The purpose of this study is to optimize the physical education process optimization alongside the improvement of 15-17 year-old males' cognition embodying boxing exercises. The objective of the study was fulfilled by accomplishing some particular steps including a) determination of influence factors of box exercises on cognitive processes and sensorimotor reaction speed, b) development of author program for 15-17 year-old males incorporating boxing exercises, and c) experimentally approve its efficiency. Research paper analysis, pedagogical experiment, psycho-diagnostics, and mathematical statistics were applied during the course of this study.

\section{Literature Review}

Latest research paper analysis showed that numerous investigations were conducted into the area of psychophysical characteristics and their dependencies on their motional training. In the studies of Bodnar, Rymar, Solovei, Malanchuk, \& Datskiv, 2015 the dependence of the adolescent nervous system functional state on the physical activity levels was proven. Higher cognition efficiency formation and psycho-emotional toughness problems are tackled in 
medicine, professional education (Bodnar, Dukh, Vovkanych, \& Kindzer, 2012) and in sports and physical education phychology (Solovei \& Rymar, 2013; Solovei, 2002). In the literature, there is a great number of studies dedicated to investigate into psychophysiological indicators of different training level of athletes in discrete sports (Brychta, Hojka, Heller, \& Rudaв, 2013). It was established that skilled sportsmen score higher in examinations of visual shortterm memory, functional mobility, and neural processing strength. The sensorimotor reaction peculiarities of different sports disciplines are described in the study (Vovkanych, Dunets-Lesko, Penchuk, \& Kachmar, 2015) and the indexes obtained can be considered as model during athletic selection or sportsmen functional preparation assessment. The velocity of sensorimotor reactions, cognitive and coordination capacities in the perennial sports training programs for boxers are studied in the literature of Nikitenko, 2019; Dudnik, Miroshnichenko, Kostynska, \& Kuzmik, 2019; Obmiński, Mroczkowska, Kownacka, \& Stabno, 2011; Pic \& Jonsson, 2021.

The instances of boxing means incorporation into the physical education processes of high school students are mentioned in the study of Novokshonov, Solovei, Yaroshyk \& Rymar, 2019. It was identified that the pupils had expressed high interest in martial arts, especially boxing. The experimental author program implementation likely positively impacted coordination capacities of adolescent boys and girls. It is important to mention that studies dedicated to delve into psychophysiological functionality, cognition, and sensorimotor reaction optimizations of the high school and higher educational institution students are of rare occurrence.

\section{Methodology}

The study has been conducted during 2019 - 2020. The initial stage of the study was manifested through collection and analysis of research papers and documentary materials devoted to cognition formulation processes peculiarities of 15-17 year-old males, and impact of boxing and physical exercises on sensorimotor reaction velocity and cognitive efficiency. The object of the study was the process of physical education, the subject of the study were the features of the use of boxing in this process. The obtained results allowed determining the purpose of the work, to specify the tasks and to scientifically substantiate the methodical approach to their solution.

To meet the research goals, we conducted the ascertaining and forming pedagogical experiments, during which the method of psychodiagnostics of psychophysiological reactions was used. 
The psychodiagnostics were performed by testing that incorporated a computer system of emergency-psychotest, version 1.8.0.0 2016, and serial number 05775B. The following methods were used: "Attention assessment", which is used to diagnose stability and concentration, and it allowed us to conduct the analysis of a number of indicators - average reaction time, the central nervous system functional levels, reaction stability, nervous system functional capabilities, performance assessment by the neural system functional levels, performance assessment by the stability of the reactions, efficiency assessment by the levels of the functional capabilities, errors of anticipation, errors of delay, stability of attention and concentration; the "Noise Resistance" method was used to determine the ability to concentrate in the presence of sound and visual interference; method "Red and black Schulte-Platonov tables" (modified version) allowed to analyze the indicators of volume, switching and distribution of attention. Student's t-test and Wilcoxon's test were used to determine the degree of significance of the differences.

In order to determine the influence of boxing on cognitive processes and the speed of sensorimotor reactions, a confirmatory experiment was conducted. The ascertaining experiment was attended by 15 promising athletes aged 15-17, who have 5-7 years of experience in boxing and perform at international competitions, and 30 students, aged 15-17 years, of vocational lyceum, who have no abnormalities in health.

A comparative analysis of the results of testing the psychophysiological reactions of the two groups according to the methods of "Attention Assessment", "Noise Resistance", "Red and Black Schulte-Platonov Tables" was performed. Student's T-criterion was used to determine the degree of difference reliability.

The obtained results became the basis for the development of the author's program with the use of boxing means aimed at optimizing cognitive processes and sensorimotor reactions for 15-17 year-old males.

In order to test the effectiveness of the author's program with the use of boxing exercises in 2019 (October-December), a pedagogical experiment was conducted, which lasted 3 months. The author's program was introduced into physical education classes of a professional lyceum at the beginning of the main part of the lesson. The experiment involved 30 boys aged 15-17, who are in the main medical group due to their health condition. At the beginning and at the end of the experiment, testing of psychophysiological reactions of the participants of the experiment and comparative analysis of testing indicators were performed. The Wilcoxon $\mathrm{T}$ test was used to determine the degree of difference reliability. 


\section{Study Results}

The results of the confirmatory experiment conducted to study the effect of boxing on cognitive processes and the speed of sensorimotor reactions showed that boxers have significant differences in a number of indicators (Table 1).

The comparative analysis of test results by the method of "Attention assessment" showed that boxers have probably better indicators of the average reaction time ( $\mathrm{t}=2.513$ at $\mathrm{p}<0.05)$. The average reaction time in the group of athletes was $254.4 \pm 8.7 \mathrm{~ms}$, and in the participants of the general group $296.26 \pm 3.85 \mathrm{~ms}$.

The indicators of the functional level of the nervous system in the group of boxers got $4.19 \pm 0.9$ units, and in the general group it was $3.87 \pm 0.15$ units. In the analysis of indicators, it was taken into account that the functional level of the nervous system is considered high at $5.1 \leq$ units; the lower the indicator, the lower the functional level. The mathematical analysis proved a statistically significant difference between the indicators of the two groups $(t=2.513$ at $\mathrm{p}<0.05$ ). This proves that boxers probably have a higher functional level of the nervous system.

The average stability of the reaction in the group of boxers got $1.92 \pm 0.1$ units, in the general group $1.4 \pm 0.15$ units. In the analysis, it is necessary to consider that the higher indicator is the best $(2.6 \leq$ high level of stability of attention). The mathematical analysis proved a statistically significant difference between the indicators of the two groups in the stability of reactions $(t=2.248$ at $\mathrm{p}<0.05$ ). Therefore, boxers probably have a higher level of stability or stability of the reaction.

The indicators of the level of functional capabilities of the nervous system in the group of boxers got $3.33 \pm 0.11$ units, in the general group $2.7 \pm 0.2$ units. When the level of functionality is assessed, it is necessary to take into account that the higher indicator, the better $(4.7 \leq$ high level). The mathematical analysis proved a statistically significant difference between the indicators of the level of functionality of the nervous system of the two groups $(\mathrm{t}=3.001$ at $\mathrm{p}<0.05)$. This suggests that boxers probably have a higher level of nervous system functionality capabilities.

The analysis of indicators for assessing the efficiency of the nervous system in a group of boxers got $4.18 \pm 0.09$ units compared to the results in the general group of $3.86 \pm 0.05$ units. The mathematical analysis proved a statistically significant difference between the indicators of performance assessment by the functional level of the system of the two groups $(t=3.190$ at $\mathrm{p}<0.05$ ). Accordingly, boxers are likely to have a higher score on the functional level of the nervous system. 
The average performance of the stability of attention in the group of boxers got $1.93 \pm 0.09$ units, in the general group $1.63 \pm 0.09$. The mathematical analysis proved a statistically significant difference between the indicators of performance assessment for the stability of the attention of the two groups $(t=2.410$ at $\mathrm{p}<0.05)$. This proves that boxers have a probably higher rating of performance for stability of attention.

The analysis of performance assessment indicators according to the level of functional capabilities of the nervous system in the group of boxers $3.33 \pm 0.11$ units, in the general group $2.9 \pm 0.09$. The mathematical analysis proved a statistically significant difference between the indicators of assessment of the level of functionality of the two groups $(t=3.190$ at $p<0.05)$. Accordingly, boxers are likely to have a higher assessment of performance by the level of functionality of the nervous system

In the analysis of most indicators by the method of "Noise Resistance" significant differences were found in the indicators of response speed. The average rate of response to sound and visual interference in the group of boxers $300.62 \pm 8.86 \mathrm{~ms}$, in the general group $333.36 \pm 5.73 \mathrm{~ms}$. The mathematical analysis proved a statistically significant difference between the noise immunity of the two groups $(t=3.104$ at $\mathrm{p}<0,05)$. Thus, boxers have probably a better response time to visual and auditory interferences, respectively, a higher level of noise immunity. The analysis of the results of research according to the method of "Red and black Schulte-Platonov tables" (modified version) that boxers have significant differences in the volume, distribution of attention and the number of errors in testing.

The average indicators of the amount of attention in the group of athletes $47.27 \pm 2.59$ points, which corresponds to the average level on the rating scale according to the method of Schulte-Platonov. The average indicators of the general group are $56.03 \pm 2.76$ points, which corresponds to a level below the average. The mathematical analysis has shown that boxers have a probably better $(\mathrm{t}=2.317$ at $\mathrm{p}<0.05)$ amount of attention, can capture more objects in a limited period of time.

The average indicators of the distribution of attention in the group of athletes $74.0 \pm 6.99$ points, which corresponds to the average level on the rating scale according to the method of Schulte-Platonov. The average indicators of the general group are $99.7 \pm 5.63$ points, which corresponds to a level below the average. Boxers have a significantly better $(t=2.793$ at $\mathrm{p}<0.05)$ ability to pay attention to or observe two or more objects at the same time.

The indicators of errors, when the method of Schulte-Platonov was performed, were $2.4 \pm 0.6$ points in the group of boxers, and $4.63 \pm 0.6$ pointsin the general group. The mathematical analysis of the results of the study proves 
that the boxers made probably less $(t=2.624$ at $\mathrm{p}<0.05)$ errors when performed the test, which demonstrates they have the best ability to concentrate.

Table 1 Results of Testing the Psychophysiological Reactions

\begin{tabular}{|l|l|l|l|}
\hline Methods & $\begin{array}{l}\text { Boxers } \\
(\mathrm{n}=15)\end{array}$ & $\begin{array}{l}\text { General } \\
\text { group (n=30) }\end{array}$ & $\begin{array}{l}\text { Student's T- } \\
\text { criterion (p }<0,05)\end{array}$ \\
\hline "Attention assessment" & $254.4 \pm 8.7$ & $296.26 \pm 3.85$ & 2.513 \\
\hline Average reaction time (ms) & $4.19 \pm 0.9$ & $3.87 \pm 0.15$ & 2.513 \\
\hline Central nervous system functional levels (units) & $1.92 \pm 0.1$ & $1.4 \pm 0.15$ & 2.248 \\
\hline Reaction stability (units) & $3.33 \pm 0.11$ & $2.7 \pm 0.2$ & 3.001 \\
\hline Nervous system functional capabilities (units) & $4.18 \pm 0.09$ & $3.86 \pm 0.05$ & 3.190 \\
\hline $\begin{array}{l}\text { Performance assessment by the neural system } \\
\text { functional levels (units) }\end{array}$ & & $1.63 \pm 0.09$ & 2.240 \\
\hline $\begin{array}{l}\text { Performance assessment by the stability of the } \\
\text { reactions (units) }\end{array}$ & $1.93 \pm 0.09$ & 3.190 \\
\hline $\begin{array}{l}\text { Efficiency assessment by the levels of the } \\
\text { functional capabilities (units) }\end{array}$ & $3.33 \pm 0.11$ & $2.9 \pm 0.09$ & \\
\hline "Noise Resistance" & & & \\
\hline $\begin{array}{l}\text { Average rate of response to sound and visual } \\
\text { interference (ms) }\end{array}$ & $\begin{array}{l}300.62 \pm 8.8 \\
6\end{array}$ & $333.36 \pm 5.73$ & 3.104 \\
\hline "Red and black Schulte-Platonov tables" & $67.27 \pm 2.59$ & $56.03 \pm 2.76$ & 2.317 \\
\hline Amount of attention (units) & $74.0 \pm 6.99$ & $99.7 \pm 5.63$ & 2.793 \\
\hline Distribution of attention (units) & $2.4 \pm 0.6$ & $4.63 \pm 0.6$ & 2.624 \\
\hline Errors (units) &
\end{tabular}

Thus, a comparative analysis of the results of tests by the method of "Attention assessment" showed that boxers have probably better average response time, functional level of the central nervous system, stability of reactions, functional capabilities of the nervous system, assessment of performance by functional level of the system, and assessment of efficiency by level of functionality. No significant differences were observed in the indicators ofthe errors of anticipation, delay errors, stability of attention, and concentration.

The comparative analysis of the results of tests by the method of "Noise Resistance" showed that boxers have probably the best average response time to sound and visual interference, and, accordingly, a higher level of noise immunity.

The analysis of the results of Schulte-Platonov's attention tests showed that boxers have probably better indicators of attention span, attention distribution and fewer errors during testing (Table 1).

The conducted studies show that boxing has a positive impact on cognitive processes and the speed of sensorimotor reactions of boxers, which became the basis for the development of the author program. The author program was developed taking into account the peculiarities of physical development of boys aged 15-17, and was aimed at activating the cognitive processes of memory and 
attention, the manifestations of sensorimotor reactions of simple and complex responses through the use of special non-contact simulation exercises.

The program of classes was divided into two stages: preparatory (6 lessons) and basic (30 lessons). The tasks of the preparatory stage included learning the technique of performing simulation basic boxing exercises - boxer's stand, movement in the boxer's stand, straight, bottom, and side blows, and some combinations of two blows. The tasks of the main stage were optimization of cognitive processes and sensorimotor reactions, as well as performing some blocks of combinations of 8 special boxing exercises with changes in motor tasks, direction of movement, and pace, which required attention, memory, speed of reaction, and reaction of choice in the conditions of time lack.

In order to test the effectiveness of the author program, a pedagogical experiment was conducted, which had lasted for 3 months. The author program was introduced into the regular forms of physical education lessons.

At the beginning and at the end of the experiment, the testing of psychophysiological reactions of the participants was performed.

The results obtained by the method of "Attention assessment" showed that the average time of the reaction rate before the experiment was $333.4 \pm 5.7 \mathrm{~ms}$, and after the experiment $313.7 \pm 10.5$ ms. The mathematical analysis proved a statistically significant difference between the initial and final indicators. The calculated value of the Wilcoxon $\mathrm{T}$ test, emp. $=144$ less than $\mathrm{T}(0.05)=151$ with a probability of error $\mathrm{p}<0.05$. The simple reaction time was likely improved as a result of the experiment.

The analysis of the stability of the reaction to the experiment got $1.3 \pm 0.1$ units, and after the experiment it was $1.6 \pm 0.1$ units. During the analysis, it is necessary to consider that the higher indicator, the better $(2.6 \leq$ high level of stability of reaction). The calculated value of the Wilcoxon $\mathrm{T}$ test, emp. $=133$ less than $\mathrm{T}(0.05)=151$ with a probability of error $\mathrm{p}<0.05$. As a result of the experiment, the firmness and stability of reactionslikely improved.

The analysis of tests by the method of "Noise Resistance" exhibited differences between the indicators before and after the experiment. The average reaction time according to the method of "Noise Resistance" before the experiment was $375.7 \pm 11.9 \mathrm{~ms}$, and after the experiment $333.4 \pm 5.7 \mathrm{~ms}$. The calculated value of the Wilcoxon $\mathrm{T}$ test was emp. $=112$ less than $\mathrm{T}(0.05)=151$ with a probability of error $\mathrm{p}<0.05$. The response time to visual and auditory disturbances probably improved, respectively, increased the level of noise immunity, with the experiment having impact on the participant group members.

The analysis of the results of research according to the method of "Red and black Schulte-Platonov tables" (modified version) showed that, as a result of the experiment, there were significant differences in the volume and distribution of attention. 
The average indicators of the amount of attention to the experiment are $56.03 \pm 2.76$ points, which corresponds to a level below the average on the scale of evaluation by the method of Schulte-Platonov. The average after the experiment is $42.8 \pm 1.9$ points, which corresponds to the average level. The mathematical analysis proved a statistically significant difference between the initial and final indicators. The calculated value of the Wilcoxon $\mathrm{T}$ test was emp. $=61.5$ less than $\mathrm{T}(0.05)=151$ with a probability of error $\mathrm{p}<0.05$.

The indicators of the distribution of attention to the experiment got $99.1 \pm 5.6$ points, which corresponds to a level below the average on the scale of evaluation by the method of Schulte-Platonov. The average values after the experiment were $53.5 \pm 2.4$ points, which corresponds to a level above the average. The mathematical analysis proved a statistically significant difference between the initial and final indicators. The calculated value of the Wilcoxon test $\mathrm{T}$ was emp. $=7$ is less than $\mathrm{T}(0.05)=151$ with a probability of error $\mathrm{p}<0.05$. The experiment probably improved the distribution of attention, improved the ability to simultaneously focus on two or more objects and simultaneously perform actions with them or observe them.

At the same time, the mathematical analysis of switching of attention and of errors in the performance of the testing proves that there is no statistically significant difference between the initial and final indicators.

The results of the study confirm the positive effect of the experimental program on the psychophysical indicators of the speed and stability of the reactions, the speed of reactions to visual disturbances, the volume and distribution of attention, which, in turn, proves the effectiveness of the author program.

\section{Discussion and Conclusions}

The results of the study showed better ability of boxers to react quicker, as well as that the athletes have higher indicators of functional capabilities and efficiency of the nervous system, reaction stability, better response time to visual and auditory interferences, better ability to simultaneously pay attention to two or more objects and simultaneously interact with them, coverage of more objects in a limited period of time and concentration, which proves the positive impact of boxing on cognition processes. The significance of differences was confirmed by Student's T-test $(\mathrm{p}<0.05)$.

The obtained results became the basis for the development and implementation of the author program with the use of non-contact special boxing exercises aimed at activating cognitive processes and the speed of sensorimotor reactions. 
As a result of the pedagogical experiment, significant changes were observed in a number of indicators of psychophysical functions of boys aged 1517. After the implementation of the author program, the indicators of the average reaction time, the stability of the reaction, and, accordingly, the assessment of the efficiency of the nervous system by the stability of attention probably improved. The response time to visual and auditory disturbances, volume and distribution of attention were also likely to improve. The significance of differences was confirmed by the Wilcoxon T test $(p<0.05)$.

The results of the study confirm the positive impact of the experimental program on psychophysical parameters, which proves its effectiveness.

Our research has confirmed the findings of many experts that exercise has a positive effect on cognitive function. Dividing cognitive skills into types of attention and speed of sensorimotor reactions, the authors (Heppe, Kohler \& Fleddermann, 2016; Bianco, Russo, Perri, \& Berchicci, 2017; Pic \& Jonsson, 2021) found convincing evidence that cognitive skills can be transferred from specific sports to the general context. The authors argue that the sport is a moderator of sports-cognitive relations, with a better effect in martial arts than in team and individual sports (Heppe et al., 2016; Bianco et al., 2017). Martial arts require quick action, but preparatory brain activity can vary depending on the practical activity in a particular sport. Studies by (Bianco et al., 2017; Vovkanych et al., 2015) proved that boxers show better time of sensorimotor reactions than fencers and karate sportsmen, but worse accuracy than fencers.

The high popularity of boxing among young peoplein Ukraine, the availability of exercises and a positive impact on cognitive functions determine the introduction of this form of sport in the process of physical education. Studies by (Bodnar et al., 2012) show a higher mental resilience of students who use boxing and aerobics during physical education than when using volleyball and sambo, but no differences in sensorimotor reaction performance. Whereas, as a result of our research and implementation of the developed author's program with the use of non-contact special boxing exercises, positive changes were observed in the indicators of sensorimotor reactions, reaction stability and nervous system efficiency. Thus, the developed author's program with the use of boxing exercises can be implemented in the process of physical education and recommended for the formation of a number of specific psychophysical qualities of most modern professions. 


\section{References}

Bianco,V., Russo, F., Perri, R., \& Berchicci, M. (2017). Different proactive and reactive action control in fencers' and boxers' brain. Elsevier-Neuroscience, 343, 260-268. DOI: https://doi.org/10.1016/j.neuroscience.2016.12.006.

Bodnar, I., Dukh, T., Vovkanych, L., \& Kindzer, B. (2012). Shvydkist sensomotornykh reaktsii ta kohnityvnykh protsesiv u studentiv vyshchykh navchalnykh zakladiv humanitarnykh spetsialnostei. Fizychna aktyvnist, zdoroviai sport, 4(10), 3-9. Retrieved from: http://repository.ldufk.edu.ua/handle/34606048/5976.

Bodnar, I., Rymar, O., Solovei, A., Malanchuk, H., \& Datskiv, P. (2015). Obiektyvni kryterii dlia vyznachennia funktsionalno-rezervnykh mozhlyvostei uchniv serednoho shkilnoho viku. Pedahohika, psykholohiia ta medyko-biolohichni problem fizychnoho vykhovannia i sportu, 11, 11-19. Retrieved from: https://www.sportpedagogy.org.ua/html/journal/ 201511/PP201511.pdf\#page $=12$.

Brychta, P., Hojka, V., Heller, J., \& Ruda, T. (2013). A comparison of reaction times of boys and girls aged 10-11 and 14-15 years. Trends in Sport Sciences, 20 (3), 147-152. Retrieved from: https://www.wbc.poznan.pl/dlibra/publication/387185/edition/299310?l anguage $=$ pl\#description.

Computer system of emergency-psychotest. (2016). Retrieved from: https://neurosoft.com/ru/ catalog/psycho/expert.

Dudnik, O., Miroshnichenko, V., Kostynska, O., \& Kuzmik, V. (2019). Vplyv intelektualnykh vprav na pokaznyky shvydkosti i pryiniattia taktychnykh rishen bokseramy 11-12 rokiv. Fizychna kultura, sport ta zdorovia natsii: zbirnyk naukovykh prats, 7(26), 170-174. Retrieved from:https://93.183.203.244:80/xmlui/handle.

Heppe, H., Kohler, A., \& Fleddermann, M. (2016). The Relationship between Expertise in Sports, Visuospatial, and Basic Cognitive Skills. Front. Psychol., 1-14. DOI: https://doi.org/10.3389/fpsyg.2016.00904.

Nikitenko, S. (2019). Pidhotovka bokseriv-pochatkivtsiv u vyshchomu navchalnomu zakladi. Navchalno-metodychnyi posibnyk., 91. Retrieved from: http://repository.ldufk.edu.ua/ handle/34606048/23442.

Novokshonov, I., Solovei, A., Yaroshyk, M., \& Rymar, O. (2019). Udoskonalennia koordynatsiinykh zdibnostei uchniv starshykh klasiv zasobamy boksu. Visnyk Prykarpatskoho universytetu. Seriia: Fizychna kultura, 33, 67-73. Retrieved from: http://repository.ldufk.edu.ua/bitstream/34606048/22391/1/Untitled.FR 12.pdf.

Obmiński, Z., Mroczkowska, H., Kownacka, I., \& Stabno, J. (2011). Personality traits and eye-hand coordination in less- and more succesful young male boxers. Journal of Combat Sports and Martial Arts, 2 (2), 83-89. Retrieved from: https://journals.index copernicus.com/search/article?articleId=20090.

Pic, M., \& Jonsson, G. (2021). Professional Boxing Analysis with T-Patterns. ElsevierNeuroscience, 232, 113329. DOI: http://doi.org/10.1016/j.physbeh.2021.113329.

Solovei, A. (2002). Spetsialni sylovi yakosti dziudoistiv ta yikh rozvytok na etapi spetsializovanoi bazovoi pidhotovky. Avtoreferat kandydatska dysertatsiia Lviv, LDIFK, 20. Retrieved from: http://repository.ldufk.edu.ua/bitstream/34606048/ 2382/1/solovey_a_v.PDF.

Solovei, A., \& Rymar, O. (2013). Osoblyvosti zastosuvannia zasobiv atletyzmu v fizkulturnoozdorovchykh zaniattiakh zi studentamy vyshchykh navchalnykh zakladiv. Fizychna 
Solovey et al., 2021. The Influence of Boxing Exercises on the Cognitive Processes and Speed of Sensorimotor Reactions of 15-17 Years Old Boys

aktyvnist, zdoroviai sport, 4(14), 73-78. Retrieved from: http://sportscience.ldufk.edu.ua/index.php/fazis/article/view/179/172.

Vovkanych, L., Dunets-Lesko, A., Penchuk, A., \& Kachmar, P. (2015). Osoblyvosti sensomotornykh reaktsii sportsmeniv riznykh sportyvnykh spetsializatsii. Fizychna aktyvnist, zdoroviai sport, 2, 17-26. Retrieved from: http://repository.ldufk.edu.ua/handle/34606048/5848. 